\title{
Article \\ A Performance Comparison of Pilot-Scale Sand Filtration and Membrane Filtration of Glafkos River Water
}

\author{
Fotios K. Katrivesis ${ }^{1}$, Varvara Sygouni ${ }^{2,3}{ }^{(0)}$, Christakis A. Paraskeva ${ }^{2,3, *}$ (i) and Vagelis G. Papadakis ${ }^{1}$ \\ 1 Department of Environmental Engineering, University of Patras, GR-30100 Agrinio, Greece; \\ fkatrivesis@gmail.com (F.K.K.); vgpapadakis@upatras.gr (V.G.P.) \\ 2 Department of Chemical Engineering, University of Patras, GR-26504 Patras, Greece; sygouni@upatras.gr \\ 3 Foundation for Research and Technology, Hellas, Institute of Chemical Engineering Sciences, \\ FORTH/ICE-HT, GR-26504 Patras, Greece \\ * Correspondence: takisp@chemeng.upatras.gr; Tel.: +30-261-099-7252
}

Citation: Katrivesis, F.K.; Sygouni,

V.; Paraskeva, C.A.; Papadakis, V.G. A

Performance Comparison of

Pilot-Scale Sand Filtration and Membrane Filtration of Glafkos River Water. J. Mar. Sci. Eng. 2021, 9, 203.

https://doi.org/10.3390/jmse9020203

Academic Editor:

Chrysostomos Stylios

Received: 14 January 2021

Accepted: 11 February 2021

Published: 16 February 2021

Publisher's Note: MDPI stays neutral with regard to jurisdictional claims in published maps and institutional affiliations.

Copyright: () 2021 by the authors. Licensee MDPI, Basel, Switzerland. This article is an open access article distributed under the terms and conditions of the Creative Commons Attribution (CC BY) license (https:// creativecommons.org/licenses/by/ $4.0 /)$.

\begin{abstract}
Surface-water treatment plants use the flocculation-precipitation method followed by gravity filters to remove suspended solids. In the present work, the replacement of gravity filters with ultrafiltration membrane units is suggested to improve the efficiency of water treatment and to reduce fixed and operational costs. A parametric pilot-scale study was conducted to compare the filtration efficiency of a deep bed and a membrane module for water-simulating river water of various turbidity degrees. Suspensions of kaolinite were prepared to simulate turbidity of the Glafkos River, Achaia Region of Greece and were filtered using a laboratory sand-bed column and a pilot ultrafiltration (UF) membrane unit. Operational parameters such as the particle concentration ratio, the flow rate, and the filter head loss were studied in the case of the granular bed. In the case of membrane filtration, the permeate flux, turbidity, and membrane permeability loss due to fouling were tested. A discussion in terms of the operational cost and environmental impacts was performed. Filtration capacity of the sand filter is a decreasing function of the flow rate and it was found less efficient than membrane ultrafiltration for increased turbidity or increased particle concentration values. Membrane ultrafiltration could achieve long-term economic profit while it is characterized by minimum environmental impact since the use of chemical reagents and the production of waste sludge are limited.
\end{abstract}

Keywords: water treatment; membrane ultrafiltration; sand-bed filtration; particle size distribution; sustainable development

\section{Introduction}

Water, a basic element for life, should be used and consumed with extreme attention and according to the 5Rs approach (Recovery, Reduction, Recycling, Resourcing and Reuse): Water Recovery from storms, the Reduction of water consumption, the Recycling of less polluted water used in household activities, the Resourcing of water from toilets, and the Reuse of treated urban wastewater compose the 5Rs approach, and innovative solutions, strategies, and techniques are required to improve water quality and reuse it, to reduce water scarcity [1,2]. In particular in the Mediterranean region where most of the raw water and wastewater ends up to the sea, governments are obligated to follow environmentally friendly practices to protect marine life.

River water is a dispersion of inorganic and organic dissolved and colloidal matter, with various characteristics and components (salts, sugars, humic acids, etc.), microorganisms (bacteria, algae, microbes, etc.), and solids (clay, sand, silicon, etc.) [3]. Rivers and lakes are convenient and reliable surface-water sources because low-cost treatment techniques are required before water is safely used for municipal or industrial uses. Among others, one of the major problems during the treatment of surface water is the high seasonal variation of turbidity [4]. Intensive rainfall may suddenly increase the degree of river-water 
turbidities, much greater than 300 or even 1000 NTU (Nephelometric Turbidity Units), posing a problem for any type of treatment technology $[5,6]$. The usual sequence of rapid water-treatment processes includes coagulation, flocculation, sedimentation, filtration, and finally disinfection $[4,7]$. The appropriate water-treatment method depends on the raw water characteristics: composition, suspended particle zeta potential and size distribution, water viscosity and density, etc. [8-12].

In general, filtration of raw water may be realized with the use of deep sand-grain beds, granular organic carbon, membrane filtration, or a combination of different methods [4]. Treatment tests of rainfall water using sand and gravel filter and membrane showed similar filtration efficiency degree and produced non-potable water, but it met the regulations for other uses such as bathing, etc. However, the membrane used in these experiments required replacement during a four-month period [13]. Nevertheless, in the case of raw surface-water treatment for potable use, when deep-bed filters are used, chemical pretreatment is required for the efficient removal of microbial pathogens and part of the suspended solid content. When chemical pre-treatment is by-passed, a deep-bed filter may retain $\sim 69 \%$ for Giardia and $\sim 28 \%$ of initial turbidity. Adding coagulant-flocculant may increase the removal efficiency more than $95 \%$ for Giardia, $99 \%$ for total coliform bacteria and $70 \%$ for turbidity [14]. Previous study in various water sources has concluded that natural organic matter (NOM) is a major concern in water-treatment processes [15], because the appropriate dosage of coagulants is based on NOM chemical characteristics and concentrations. Remaining NOM during chlorination plays a significant role in disinfection by-product formation $[16,17]$. Recent experiments on NOM removal using pilot-scale filter columns, UF membranes, and granular-activated carbon showed higher removal of NOMs for a wider range of organics with higher and smaller molecular weights [18]. Chemical reagents used for particle coagulation have been associated with human diseases, therefore several research teams propose less hazardous green products be used at this stage [19-21].

In the case of deep-bed filtration, particle removal is the result of particle transport in the filtration medium and particle adhesion on pore surfaces [22]. The transport of particles through the granular medium depends on the gravity and hydrodynamic properties of the system. The transport mechanisms include diffusion, adsorption, and deposition of particles on grain surfaces. Parameters such as size and density of impurities, size and depth of filter medium and filtration rate affect water transport efficiency. The particle attachment/adherence on grain surfaces is determined by the surface and solution chemistry of the system [23]. These mechanisms are affected by the physicochemical properties of the suspension and the filter material, the filtration rate, and the chemical characteristics of the water [24]. Sand filtration efficiency of heavy metals and metalloids removal may be enhanced with the use of additives [18,25].

Considering filtration using membranes (micro, ultra, nano, and reverse osmosis), bacteria, and other micro-organisms, particulate matter, small pollutants and natural organic material are removed sufficiently [26,27]. The advantages of membrane technology include simple operation, low space requirements, low-pressure/high-flow operation and finally the absence of chemical treatment. The pore diameters of UF membranes, range between 1 and $100 \mathrm{~nm}$ and may retain components between 5000 and several million Dalton [28]. The retention of substances from membranes does not depend only on its pore size but also on factors such as the shape of the substances, as well as their charge and zeta potential. Membrane systems are usually operating in a closed loop, as the recycled retentate and the final concentrate are received as proportions of the feed suspension. Diffusion of molecules close to the membrane surface results to concentration polarization, creating a barrier for liquid flow and causing a flux reduction. The extent to which crossflow successfully prevents membranes from fouling depends mainly on the crossflow velocity [29]. Pollutants deposits on the membrane usually create a gel layer clogging the membrane pores and reduce filtration efficiency, phenomenon known as membrane fouling [30]. NOM are of the most common pollutants of UF membranes [18]. Periodical cleaning of membranes is required for the removal of pollutant deposits and for the increase 
of membrane's operation life. Membrane cleaning includes chemical and/or mechanical treatments [30].

In both depth-bed and membrane filtration, large amounts of water are consumed due to sludge discharge and cleaning procedures. Water losses in granular filtration systems may approach $\sim 4 \%$ of the total raw water. Backwashing of a deep filter may require $2-3 \%$ of the total raw water. Membrane filtration plants include both sludge and chemical waste streams. The sludge is made up of the blow-down or used backwash water and has a composition similar to the feed stream at slightly higher concentration. The sludge quantity varies between $2 \%$ and $10 \%$ of inflow depending on the feed water quality, the chemical pre-treatment, and whether a clarification stage precedes the process. The sludge concentration is similar to wash water from sand-bed filters. Generally, filtration practices employed in water-treatment plants produce large volume of washing water, usually $2-3 \%$ of the treatment plant flow. The cleaning frequency depends on the nature of the suspended solids in the raw water. Intensive and often backwashing affects the filter's performance and life whereas backwashing should be realized considering the kind of material and the temperature of the backwash water. Waste streams disposal is a significant issue for environment and sustainable technologies are used to minimize them [31]. Because little or no chemical treatment is used in a membrane system, the concentrate stream usually contains only the contaminants found in source water at higher concentrations and can be disposed back in the source water. However, the low efficiency of UF membranes on heavy metals removal should be combined with reverse osmosis membrane filtration or generated carbon treatment in case of surface water polluted with heavy metals [18].

Herein, depth and membrane filtration are used for the treatment of kaolinite-water suspensions in concentration values which simulate Glafkos River surface-water turbidity. Glafkos is the main water source for the Municipality of Patras, Greece, and today, water is being processed in the local treatment plant, via coagulation/flocculation/precipitation which takes place in large conical tanks using poly-aluminum chloride as coagulant and polyacrylamide as flocculant. Filtration is conducted by gravity in sand-bed filters. However, the seasonal turbidity variation of raw water channeled from Glafkos River, affects the rejection characteristics, and has significant effect on separation efficiency and chemical usage.

To improve treated water quality and to reduce the use of chemical reagents, a parametric study of filtration using depth filter and membranes, was performed for suspensions of kaolinite in concentrations equal to surface water of Glafkos River. Operational parameters such as the particle concentration ratio, flow rate and filter head loss for the filtration in the case of the granular bed, and the permeate flux, turbidity and membrane permeability in the case of membrane filtration are investigated [21].

Thus, in this practical performance analysis on the implementation of depth and membrane filtration on a water-treatment facility, a comparison of the achieved efficiencies was realized, taking also into account the reduction or even the elimination of chemical reagents usage in potable water-treatment. Based on the experimental results, optimum operation conditions were proposed, and previous technoeconomic case studies were discussed for both filtration processes.

\section{Materials and Methods}

A scheme usually followed in water-treatment plants including deep-bed or membrane filtration is presented in Figure 1. In the present study, filtration experiments of kaolinite suspensions were performed, evaluating the operational parameters for a depth sand filter and a membrane filter. Particle concentration ratio, flow rate and filter head loss were investigated in the case of the filtration through the granular bed, and the permeate flux, turbidity, and membrane permeability were tested in the case of membrane filtration. The feed water was a suspension of water with kaolinite particles in concentrations that simulates Glafkos River-water turbidity. Glafkos River is the main surface-water source for the area of Municipality of Patras. 


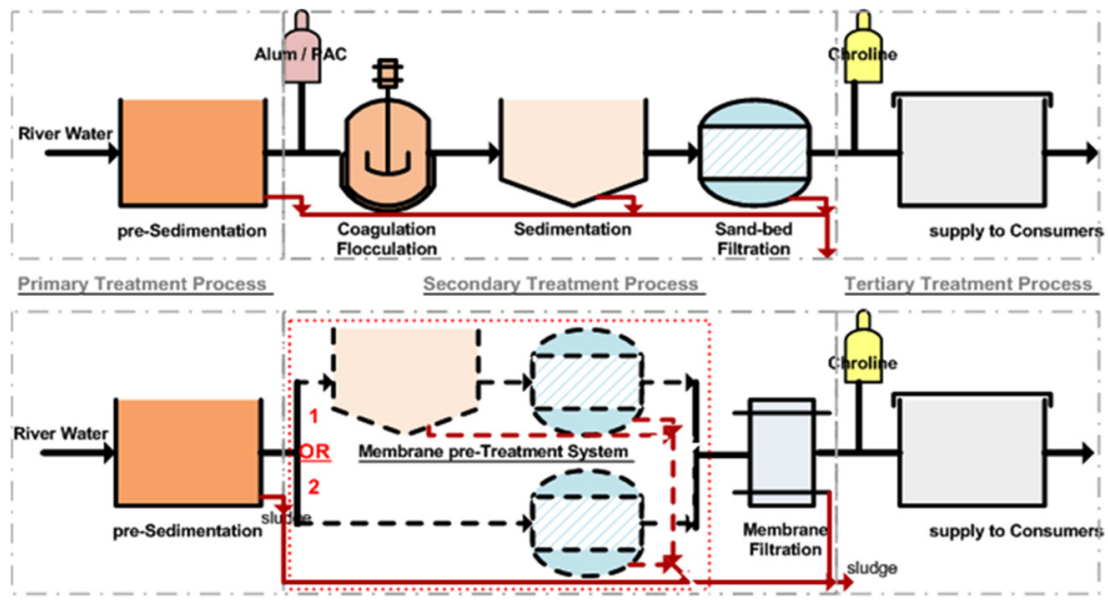

Figure 1. Deep-bed and membrane filtration detailed block diagram of a water-treatment plant.

Suspensions used in the experiments were prepared by dispersing kaolinite particles $\left(\mathrm{Al}_{2} \mathrm{Si}_{2} \mathrm{O}_{5}(\mathrm{OH})_{4} \cdot 2 \mathrm{H}_{2} \mathrm{O}, \mathrm{MW}=260.17\right.$, density $=2.6 \mathrm{gr} \mathrm{cm}^{-3}$, by Aldrich Co., Taufkirchen, Germany) in water at various concentration values. To obtain a calibration curve for turbidity versus kaolinite concentration, solutions of kaolinite of various concentration values were prepared in $600 \mathrm{~mL}$ glass vessels and turbidity was measured.

The flow rates used corresponded to the maximum, average, and low flow rates of the local municipal water treatment and resulted in velocity values for the specific sand-bed columns equal to $\mathrm{V}=1.0,1.84$ and $2.45 \mathrm{~mm} \mathrm{~s}^{-1}$.

The deep-bed filtration apparatus used for the experiments was consisted of a sand filter, a pressure measurement panel, a reservoir $\left(0.1 \mathrm{~m}^{3}\right)$ containing the suspension and a piping network (Figure 2). A centrifugal pump was driving water from the reservoir to the filter. All connections were made of PVC and a valve allowed flow direction control from top to bottom (for normal filtration operation) or from bottom to top (for fluidized bed operation and flushing). The flow rate gauge showed flow rates up to $0.1 \mathrm{~m}^{3} \mathrm{~h}^{-1}$. Filter was made of a Plexiglas cylindrical column of $90 \mathrm{~mm}$ internal diameter and was consisted of three parts: A $18 \mathrm{~cm}$ inlet which allowed water distribution in the sand bed, the sand bed with length equal to $171.5 \mathrm{~cm}$ and an outlet system of $13.5 \mathrm{~cm}$ of length, which retained the sand grains. The manometer panel was used for pressure difference measurements along the column and consisted of $9 \mathrm{Hg}$ manometers made of glass with internal diameter $3 \mathrm{~mm}$. During all the experiments, the suspensions flowed from top to bottom, a sample collected directly from the reservoir for turbidity measurement, and pressure-drop measurements were recorded at the sampling points. Samples were collected along the filter tube for turbidity, and particle concentration and particle size distribution measurements.
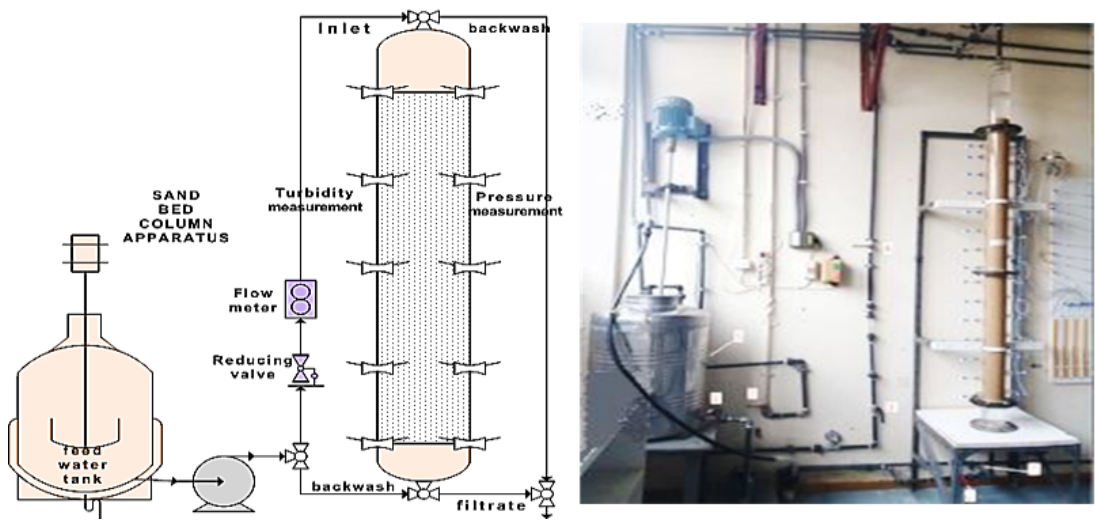

Figure 2. Deep-Bed Filtration Unit. 
The HAR P1960 (Hydro Air Research-Italy) ultrafiltration membrane unit used for the experiments operated at a crossflow model (Figure 3). Ultrafiltration membranes operation is controlled by size exclusion mechanism. River water for municipal consumption is usually characterized by high initial turbidity values, membranes with pore openings up to $100 \mathrm{~nm}$ can be used to ensure lower values of fouling index and Trans Membrane Pressure (TMP). This kind of membranes guarantee higher rejection yields of the undesirable water components (suspended particles and almost all micro-organisms) which can be achieved by varying operating conditions, such as the tangential and the crossflow rates [32]. The membrane unit was consisted of stainless-steel piping, the removable membrane module, a thermometer, two manometers at the inlet and at the outlet of the membrane module and the corresponding flow control valves (Figure 3). The ultrafiltration membrane was ceramic, made of zirconia with pore sizes at $100 \mathrm{~nm}$ and active surface equal to $0.24 \mathrm{~m}^{2}$. It was equipped with 19 feeding channels of $1020 \mathrm{~cm}$ length and $4 \mathrm{~mm}$ of diameter. The absolute water permeability was estimated equal to $1800 \mathrm{~L} \mathrm{~h}^{-1} \mathrm{~m}^{-2}$, for flow rates equal to 3.44 and $4.30 \mathrm{~m}^{3} \mathrm{~h}^{-1}$, corresponding tangential flow velocities 4 and $5 \mathrm{~m} \mathrm{~s}^{-1}$ respectively, and transmembrane pressure (TMP) equal to 1.75 bar. From a reservoir of $200 \mathrm{~L}$, the suspensions of kaolinite were introduced into the ultrafiltration module through suitable plastic piping and a centrifugal pump. Two separate outlets of the membrane unit gave the filtrate (permeate) and the retentate (concentrate) which ended at the initial tank During the experiment, samples of the permeate and the concentrate were collected for turbidity, particle size distribution and particle concentration measurements.

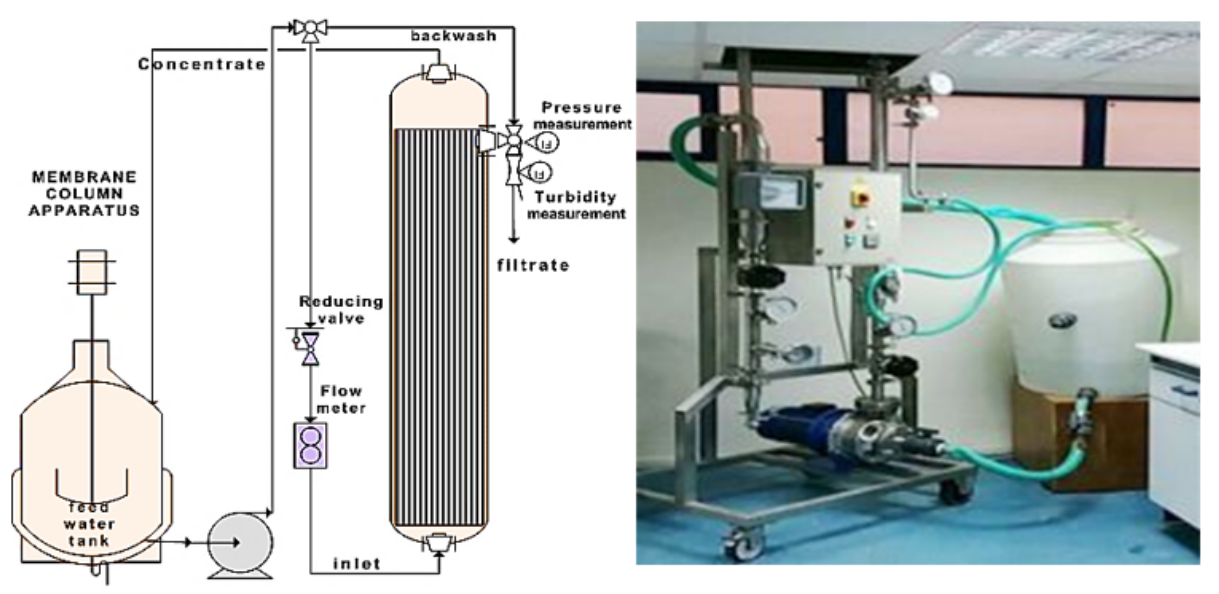

Figure 3. Ultrafiltration Membrane Unit.

The degree of turbidity for the suspensions used in the experiments was measured using the device SMART3 Colorimeter (by LaMotte Co., Chestertown, MD, USA). Sample turbidity was measured using the MLW oven (MLW Co., laboratory dryer-oven, Germany), and the AUW220 (by Shimadzu Co., Kyoto, Japan) analytical balance apparatus (2540B Standard Methods).

\section{Results}

\subsection{Deep-Bed Filtration Performance}

Particle removal using deep-bed filtration was achieved both by transferring particles through the pores between the granules and by the particle attachment to the grain surface. In deep-bed filtration experiments, the effect of superficial velocity on the process was investigated for different granular size of packing material, while other parameters such as the diameter and the total bed depth, aqueous suspension, and particle size distribution remained constant for all experiments.

Eighteen experiments were performed for various suspension initial turbidity values, $\mathrm{C}_{\text {init }}=15,70$ and150 NTU, for superficial velocity values $\mathrm{V}=1.0,1.85$ and $2.45 \mathrm{~mm} \mathrm{~s}^{-1}$ $\left(\mathrm{Q}=0.02,0.04\right.$ and $0.06 \mathrm{~m}^{3} \mathrm{~h}^{-1}$, respectively $)$, and for two different grain sizes $\mathrm{d}_{\text {grain } 1}>1 \mathrm{~mm}$ 
$(1.0-1.4 \mathrm{~mm})$ as well as $\mathrm{d}_{\text {grain2 }}<1 \mathrm{~mm}(0.6-1.0 \mathrm{~mm})$. Turbidity of 70 NTU represented a mean turbidity value of the raw water introduced in the treatment plant for a period of one year. However, in the case of superficial velocity the usual filtration rate in gravity filters of typical water-treatment plants is between 5 to $10 \mathrm{~m} \mathrm{~h}^{-1}\left(1.4 \sim 2.8 \mathrm{~mm} \mathrm{~s}^{-1}\right)$.

The normalized particle concentration (i.e., the ratio of particle concentration at a certain depth to the initial concentration of the suspension), along the depth of the sand-bed, for various filtration durations, at a moderate filtration rate (superficial velocity, $\mathrm{V}=1.85 \mathrm{~mm} \mathrm{~s}^{-1}$ ) for initial turbidity equal to $70 \mathrm{NTU}$, as well as the corresponding pressure-drop curves along the depth of the filter were summarized in Figure 4.

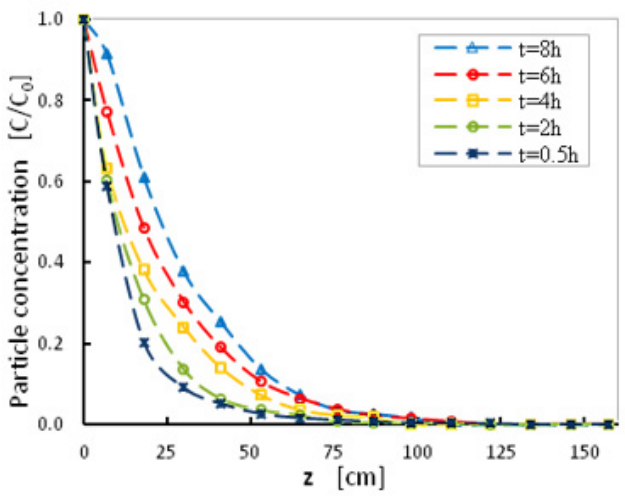

(a)

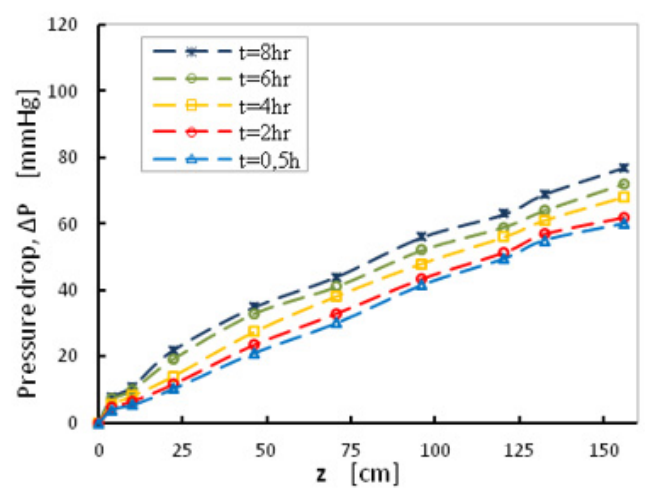

(b)

Figure 4. (a) Normalized particle concentration and (b) Pressure drop along the depth of the filter. Effect of filtration duration when $\mathrm{V}=1.85 \mathrm{~mm} / \mathrm{s}$, sand grains with fine size distribution $<1 \mathrm{~mm}$ and $\mathrm{C}_{0}=70 \mathrm{NTU}$.

Data for particle concentration at the outlet of the filter and the pressure-drop values at different depths were collected at different time intervals $(0,0.5,2,4,6$, and $8 \mathrm{~h})$. For all filtration durations, normalized particle concentration at the outlet of the filter, was reduced along the filter depth with different rates (Figure $4 \mathrm{a}$ ), as expected. The normalized particle concentration at the outlet for the same depth increased with time, showing that the filtration efficiency of the packing material is reduced gradually with time and local interstitial velocity increased considerably due to particles deposits on grain surfaces. Particle deposition resulted in permeability decrease, thus since flowrate was kept constant, the corresponding curves of pressure-drop were shifted correspondingly (Figure $4 \mathrm{~b}$ ). After eight-hour of filtration, particle concentration in the bulk flow within the filter was significant for sand-bed depths up to $50 \mathrm{~cm}$ (Figure 4a) and particle deposition took place at depths lower than $100 \mathrm{~cm}$. Measured pressure-drop values were lower than $80 \mathrm{mmHg}$ ( $\sim 0.1 \mathrm{bar})$, at the outlet of the filter $\mathrm{z}=150 \mathrm{~cm}$, which was acceptable for filter operation (Figure $4 \mathrm{~b}$ ). Figure $4 \mathrm{~b}$ shows the optimal conditions for filtration, in terms of the optimum depth before backwashing is employed to refresh the filter capacity.

The effect of initial turbidity value was tested at 15, 70, and $150 \mathrm{NTU}$, at a moderate filtration rate, with superficial velocity equal to $V=1.85 \mathrm{~mm} \mathrm{~s}^{-1}$, after $8 \mathrm{~h}$ of the initiation of the filtration process. The tested turbidity values represent turbidity of Glafkos River raw water that feed the local municipal drinking water plant, all over the year. As expected, higher values of suspension normalized concentration and pressure-drop values were obtained at different depths, for higher initial turbidity values (Figure 5). Filter efficiency decreased, and pressure-drop values increased at higher initial turbidity values. 


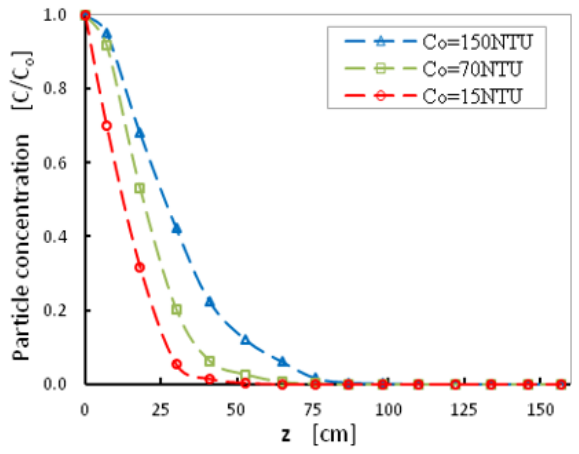

(a)

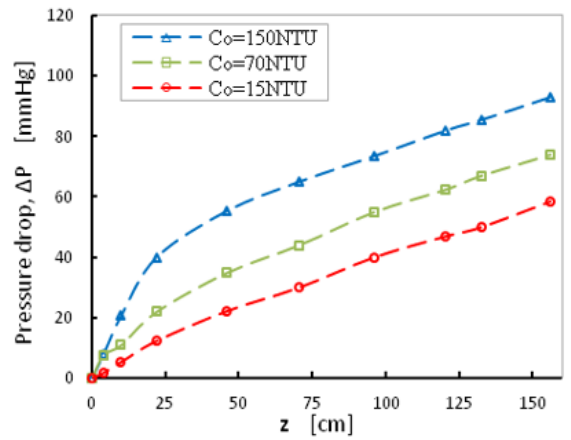

(b)

Figure 5. (a) Normalized particle concentration as a function of sand-bed depth and (b) Pressure drop as a function of sand-bed depth. Effect of turbidity value, $\mathrm{V}=1.8 \mathrm{~mm} / \mathrm{s}$, sand grains with fine size distribution $\mathrm{d}_{\text {grain }}<1 \mathrm{~mm}$ for $8 \mathrm{~h}$ of filtration.

In addition, at higher values of initial turbidity $\left(C_{\text {init }}=150 \mathrm{NTU}\right)$, the particle concentration measured at the outlet of the filter was almost zero while the corresponding curve (Figure 5a) shows that eight hours of filter operation using a $75 \mathrm{~cm}$ sand filter length was efficient for the treatment of high initial turbidity suspensions. However, a significant increase in pressure drop $(\sim 100 \mathrm{mmHg})$ was measured for the high initial turbidity due to particle deposition on pore surfaces and decrease of permeability, thus, to ensure filter efficiency filter backwashing should be done every $8 \mathrm{~h}$ (Figure 5b). Thus, choosing the appropriate operation conditions for a sand-bed filter all parameters that increase the cost of the installation and operation of the filtration unit should be considered. In typical watertreatment plants, a total particle reduction of more than $90 \%$ can be achieved under optimal flocculation/precipitation pre-treatment conditions, using electrolytes and polyelectrolytes. Thus, the water to be treated by the sand filter will have particle concentrations of less than $15 \mathrm{NTU}$, which could be treated from a sand height of $50 \mathrm{~cm}$ with relatively small changes in pressure drop (red dashed curves in Figure 5a,b).

The effect of initial superficial velocity was investigated for three values of $\mathrm{V}=1.0$, 1.85 and $2.55 \mathrm{~mm} \mathrm{~s}^{-1}$ at a moderate initial turbidity value $\mathrm{C}_{0}=70 \mathrm{NTU}$. The normalized particle concentration and the pressure drop along the filter were measured for $8 \mathrm{~h}$ of filtration (Figure 6). The lower normalized particle concentration was obtained for the experiment at the lowest superficial velocity $(\mathrm{V}=1.0 \mathrm{~mm} / \mathrm{s})$, while for the higher value of $\mathrm{V}=2.55 \mathrm{~mm} \mathrm{~s}^{-1}$ the complete removal of suspended solids was obtained after $75 \mathrm{~mm}$ of filter depth (Figure 6a). Pressure-drop values increased considerably after $8 \mathrm{~h}$ of operation and reached $120 \mathrm{mmHg}$, suggesting a cycle of backwashing every $8 \mathrm{~h}$.

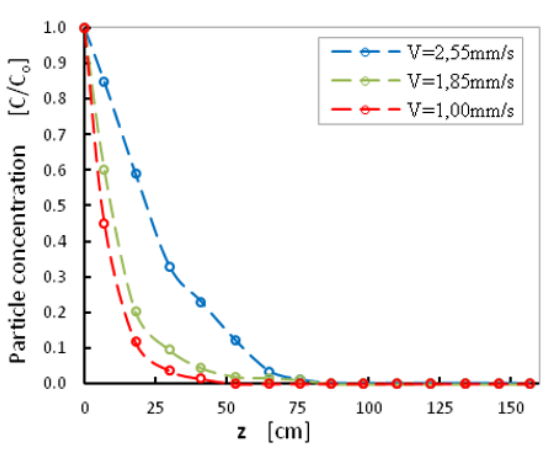

(a)

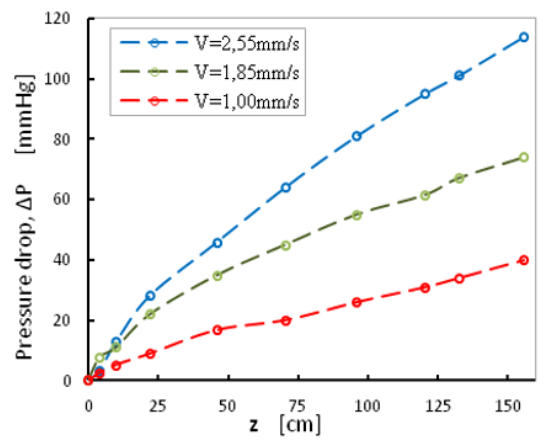

(b)

Figure 6. (a) Normalized particle concentration versus sand-bed depth and (b) Pressure drop versus sand-bed depth. Effect of superficial velocity for $\mathrm{C}_{0}=70 \mathrm{NTU}$, sand grains with fine size distribution $<1 \mathrm{~mm}$, for $8 \mathrm{~h}$ of filtration. 
The decision for the optimum superficial velocity shall rely on the best filtration efficiency, the lowest pressure drop and on the maximum quantities of treated water. After $12 \mathrm{~h}$ of operation and for the low velocity value of $1.0 \mathrm{~mm} \mathrm{~s}^{-1}$, the depth of the used filter with a sand-bed layer of $120 \mathrm{~cm}$ was found enough to retain all suspended particles. Considerable number of particles $\left(C / C_{0} \sim 0.1-0.2\right)$ was detected at the outlet of the filter (depth $>150 \mathrm{~cm})$ for the high velocity value $\left(\mathrm{V}=2.55 \mathrm{~mm} \mathrm{~s}^{-1}\right)$.

The effect of the sand-grain size distribution on filtration efficiency was investigated for two packing materials: $1.0<\mathrm{d}_{\mathrm{g} 1}<1.4 \mathrm{~mm}$ and $0.6<\mathrm{d}_{\mathrm{g} 2}<1 \mathrm{~mm}$, at a moderate filtration rate, with superficial velocity, $\mathrm{V}=1.85 \mathrm{~mm} / \mathrm{s}$ and initial turbidity equal to $70 \mathrm{NTU}$. During the experiments, the normalized particle concentration and the pressure drop were measured at two different filter depths $z_{1}=53 \mathrm{~cm}$ and $z_{2}=98 \mathrm{~cm}$, at different filtration durations (Figure 7). For larger grain size distribution, higher particle concentrations were detected in the bulk flow at $z_{1}=53 \mathrm{~cm}$ (red dashed line) and at $\mathrm{z}_{2}=98 \mathrm{~cm}$ (red solid line). As expected at $\mathrm{z}=98 \mathrm{~cm}$, lower particle concentrations were detected compared to those shown at $z=53 \mathrm{~cm}$, because a significant number of particles were deposited on the grain surfaces in the intermediate layer of $53-98 \mathrm{~cm}$. The same conclusion can be derived for the second set of measurements with packing material in the range $0.6-1 \mathrm{~mm}$ where more particles were retained within the filter at both filter depths (blue dashed line at $\mathrm{z}=53 \mathrm{~cm}$ and blue solid line at $\mathrm{z}=98 \mathrm{~cm}$ ). As expected, the filter with smaller grain sizes presented higher efficiency. Smaller grains are more effective due to the greater proportion of surface to volume (floc accumulation) and shorter distance between grains (bridging). On the other hand, use of grains of small size can cause greater hydraulic losses with higher pressure-drop values as Figure $7 \mathrm{~b}$ shows. It should be noted that for both grain size distributions which were tested during the filtration of identical suspensions and for identical superficial velocity, pressure-drop values were kept lower than $60 \mathrm{mmHg}$, suggesting that both cases can be considered to be optimal conditions. Therefore, from Figure 7 it can be concluded that larger size grains allow deeper penetration and result in lower hydraulic loss. To reduce particle escape from the sand-bed, a filter with higher depth should be designed.

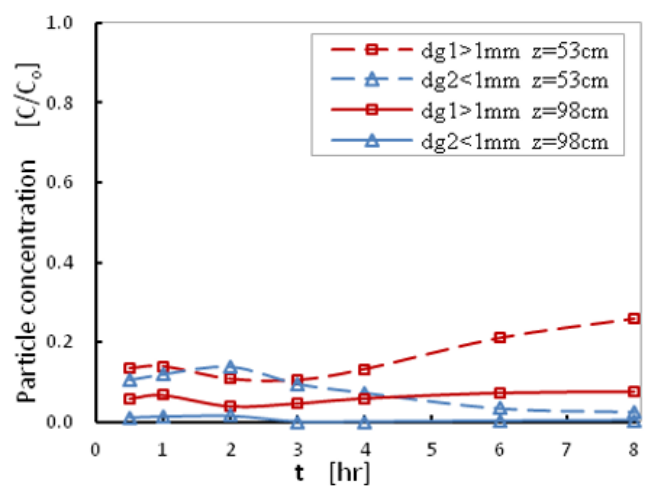

(a)

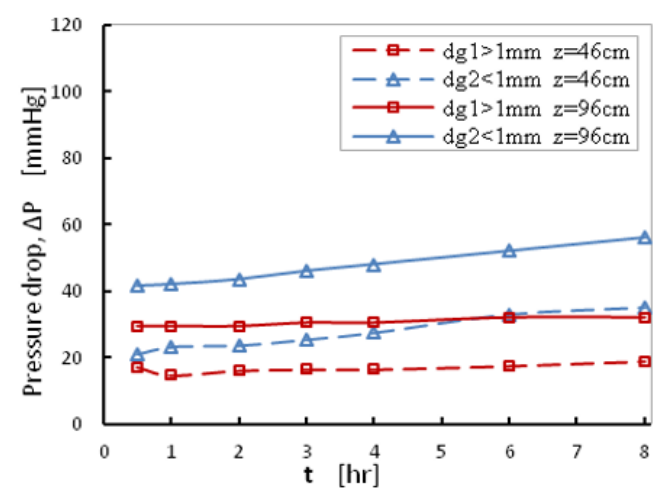

(b)

Figure 7. (a) Normalized particle concentration and (b) Pressure drop, as functions of duration time, at two different depths of the filter and two grain size distributions for packing material, at $\mathrm{C}_{0}=70 \mathrm{NTU}$ and $\mathrm{V}=1.85 \mathrm{~mm} / \mathrm{s}$.

\subsection{Membrane Filtration Performance}

For the membrane efficiency for water treatment to be investigated, kaolinite suspensions at various values of initial turbidity $\left(C_{0}\right)(15,30,45,60,70$, and $150 \mathrm{NTU})$ were prepared. During the experiments, the normalized particle concentration $\left(C / C_{0}\right)$ (i.e., the particle concentration at the permeate to the particle concentration at the feed stream) and the normalized permeate flux $Q / Q_{0}$ (i.e., permeate flux to the corresponding flux in the case of clean water) were measured at six different input turbidities (Figure 8a). As expected, the permeate flux was reduced as a function of time for higher initial turbidity 
values (Figure $8 b$ ). Membrane performance decreased as the initial value of turbidity increased.

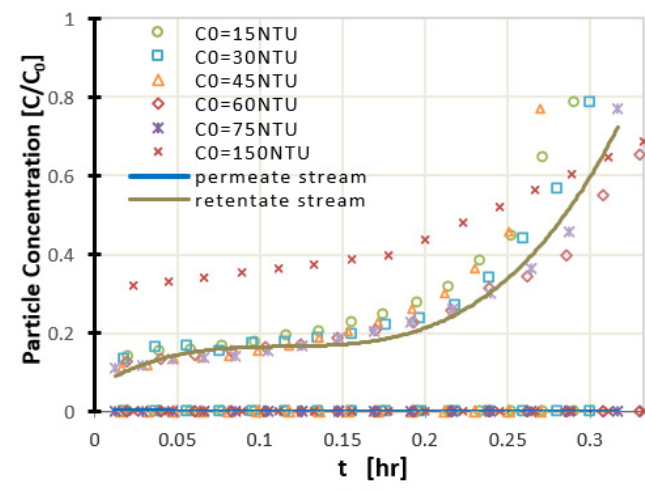

(a)

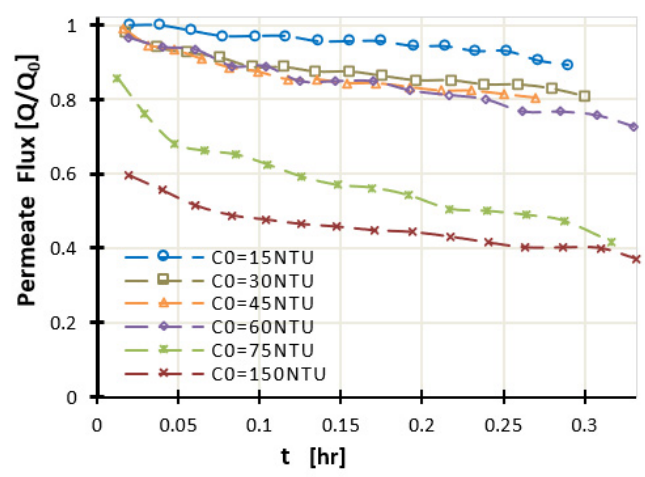

(b)

Figure 8. (a) Normalized particle concentration $C / C_{0}$ and (b) Normalized Permeate flux $Q / Q_{0}$, as functions of time. Effect of the feed stream initial turbidity on UF membrane efficiency.

The value for the turbidity of the permeate stream was zero after 5 min of membrane operation (Figure 9a), and particle concentration in the retentate (concentrate stream) increased dramatically reaching to a 7-fold increase at the end of the experiment compared to initial feed concentration. Permeability showed a $50 \%$ decrease due to membrane fouling (Figure 9b). TMP values remained constant during the entire period of the experiment (TMP $=1.0$ bar) and the flux presented a $50 \%$ reduction providing satisfactory flow rates per unit area. TMP values may increase up to 2.5 bar which might increase the initial flow rate of the permeate; however due to fouling, the permeate flowrate was reduced accordingly.

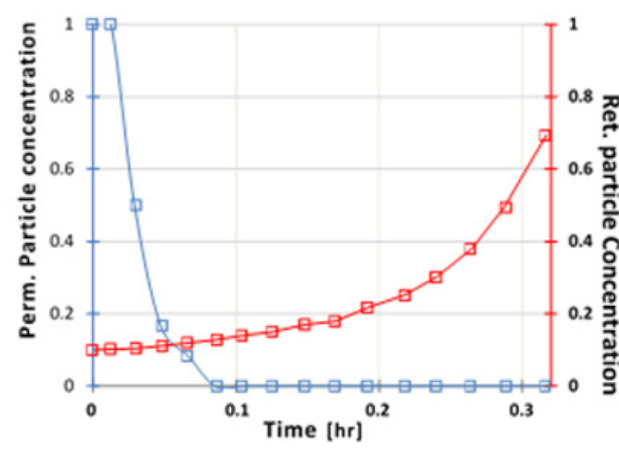

(a)

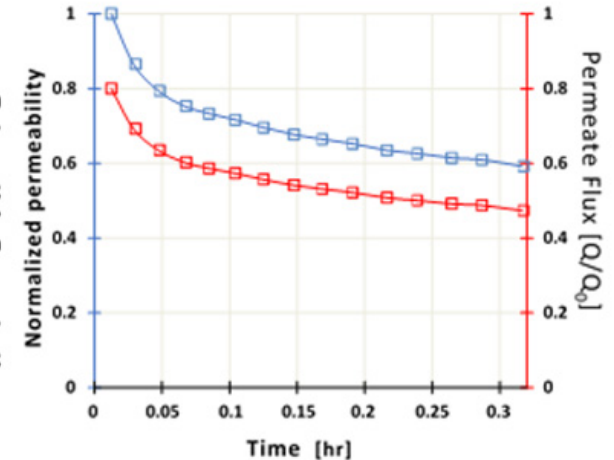

(b)

Figure 9. (a) Normalized particle concentration in the permeate (blue line) and in the retentate (red line) streams (b) Normalized Permeability (blue line) and normalized permeate flux (red line), as a function of filtration time for $\mathrm{C}_{0}=70 \mathrm{NTU}$.

As filtration continues (Figure 10b), the permeate flux decreases due to fouling concept. As the filtration continues, pressure drop, $\Delta \mathrm{P}$, increases due to membrane pores contamination. This increase has a two-fold cause. It is intensified by functional factors such as the physicochemical composition of the aqueous solution, the value of the inlet turbidity and the filtration operation time (Figure 10). However, the main factors are the intrinsic characteristics of the membrane (pore size, surface potential, velocity, and contact angle with the treatment solution). The indicator for the pollution tendency is the hydrophilic surface of the membrane characterized by the contact angle of membrane surface with water. Most of the polymers used for membrane production are extremely hydrophobic. However, this hydrophobicity leads to interactions with hydrophobic components, e.g., 
proteins resulting in the formation of a layer of contaminants on the membrane surface which causes membrane efficiency reduction.

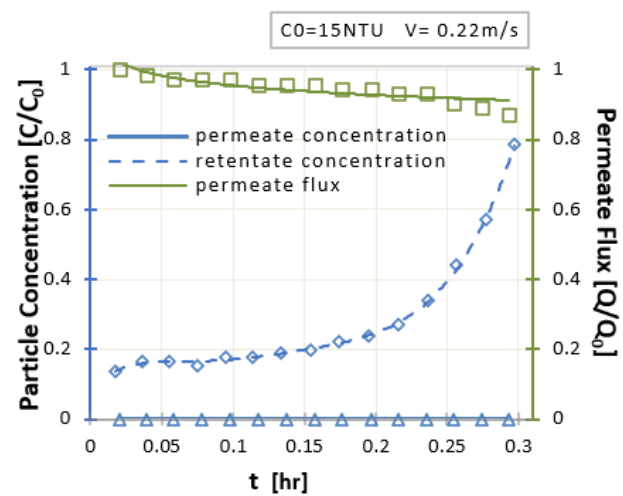

(a)

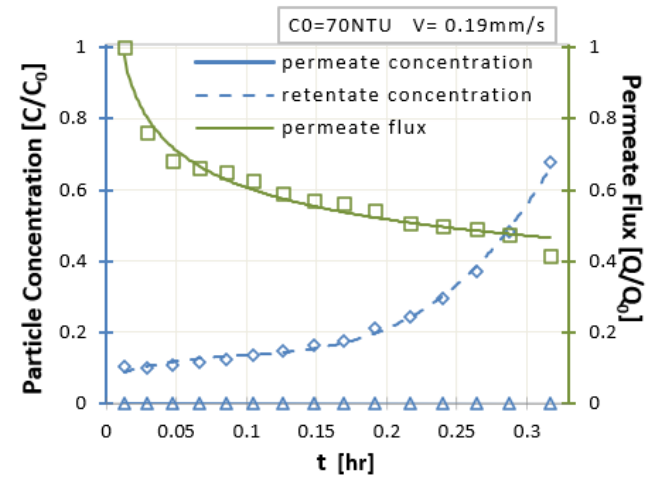

(b)

Figure 10. (a) Normalized particle concentration in the permeate (blue line) and in the retentate (dotted blue line) streams, normalized permeability flux (green line) for $\mathrm{C}_{0}=15 \mathrm{Ntu}$ and $\mathrm{V}=0.22 \mathrm{~m} / \mathrm{s}$, (b) Normalized particle concentration at the permeate (blue line) and at the retentate streams (dotted blue line) and corresponding normalized permeate flux (green line), as functions of time for $\mathrm{C}_{0}=70 \mathrm{NTU}$ and $\mathrm{V}=0.19 \mathrm{~m} / \mathrm{s}$.

During filtration using either depth filters or membranes, a systematic washing using large quantities of water is required. However, often a part of the fouling is irreversible, and membrane initial permeability cannot be recovered. Operating flux values and effluent turbidity measurements showed that UF module produced water of zero turbidity at satisfactory flow rates, independently of the initial turbidity degree. Thus, UF was found ideal for providing high quality effluent from river-water filtration. The crossflow design provided a low-fouling operation which could withstand peak turbidity events without compromising performance (i.e., permeate flux) or effluent quality.

\subsection{Prospects of Sand-Bed and Membrane fFiltration According to Cost and Environmental Impacts}

The sustainable development of water-treatment plants is part of an integrated approach to ensure environmental protection, waste minimization, and economic and social wellbeing. As regulations and legislation become stricter, water treatment becomes rigorous, intensive, and expensive. In order the cost for water treatment to be estimated five assessment aspects may be considered: capital costs, operating costs, maintenance costs, filtering quality, and total water losses. More specifically, the water treatment cost depends on the used method, water quality, the cost of coagulants, flocculants, and chemical substances used for cleaning, the amount of water losses in the liquid and solid waste stream, the energy consumption, and the required employment.

The conventional water treatment is achieved when impurities and micro-organisms are removed using physicochemical methods, when direct filtration through granular filter is not efficient to produce the desired filtrate quality. In a conventional water-treatment system, different types and amounts of NOM will enhance the effect of the coagulant to produce optimal floc size in the coagulation-flocculation process. In contrast, NOM has significant negative impact on the UF membrane fouling trend. The mechanical equipment and the use of necessary chemicals increase the capital and operational costs of conventional processing units. Except the difficulty in removing micro-organisms, the demands on skilled technical staff for waste streams residuals and sludge disposal, are additional shortcomings of conventional systems [32]. Moreover, in conventional treatment, aluminum additives during flocculation and chlorination for the removal of bacteria and viruses may increase risk to human health [33]. 
On the other hand, a UF system operating under the sieving principle is simpler, achieves complete removal of contaminants and viruses and does not produce hazardous by-products [34]. With the use of membrane systems, all soluble, colloidal, and macroscopic pollutants can naturally be separated from water. Membrane units separately or in combination with conventional processing units, using automated control systems, requires less staff. Progress in membrane technology reduced membrane production cost and combined with the small installation space requirements and the absence of chemical agents use, the implementation of membranes around the world has been intensified (Table 1) [35,36].

Table 1. Summary of environmental impacts for water treatment with conventional filtration system and ultrafiltration membranes.

\begin{tabular}{|c|c|c|c|c|c|c|}
\hline & $\begin{array}{c}\text { Energy } \\
\text { Consumption }\end{array}$ & $\begin{array}{c}\text { Use of } \\
\text { Chemicals and } \\
\text { Cost }\end{array}$ & $\begin{array}{c}\text { Waste } \\
\text { Residuals }\end{array}$ & $\begin{array}{c}\text { Water Loss } \\
\text { with Reference } \\
\text { to Treated } \\
\text { Water Volume }\end{array}$ & $\begin{array}{l}\text { Aluminum } \\
\text { Additives }\end{array}$ & $\begin{array}{c}\text { Space } \\
\text { Requirements }\end{array}$ \\
\hline $\begin{array}{l}\text { Conventional } \\
\text { Filtration } \\
\text { System }\end{array}$ & Low & High & High & $6.6 \%$ & High & Large \\
\hline UF membranes & $\begin{array}{l}\text { High ( 2 times } \\
\text { higher) }\end{array}$ & $\begin{array}{c}\text { Low }(\sim 43 \% \\
\text { lower })\end{array}$ & Low & $\sim 11 \%$ & No aluminum & $\begin{array}{c}\text { Small }(69.6 \% \\
\text { less space) }\end{array}$ \\
\hline
\end{tabular}

Nevertheless, membrane operation is characterized by higher energy consumption, which increases with increasing TMP, a drawback which may be overcome by using lowpressure membrane systems or submerged vacuum membrane systems. Today, scientists are focusing on low-pressure ultrafiltration systems as they have foreseen a promising process for drinking water production.

The advantage of membrane filtration performance and the resulting improvement has been examined in a case study, in the Eastern Mediterranean [37]. It was estimated that the extra cost of membrane filtration was saved by chemicals and consumables cost, while operating and maintenance water costs were $0.41 € \mathrm{~m}^{-3}$ for the conventional depth filtration and $0.46 € \mathrm{~m}^{-3}$ in the case of UF membrane. Capital expenditure and operating costs are summarized in Table 2.

Table 2. Total water cost comparison for the two different treatment options.

\begin{tabular}{ccccc}
\hline \multirow{2}{*}{ Parameter } & \multicolumn{2}{c}{ Conventional Filtration System } & \multicolumn{2}{c}{ Ultrafiltration Membranes } \\
\cline { 2 - 5 } & $\mathbf{k . \ell}$ & $\mathbf{\epsilon} / \mathbf{m}^{\mathbf{3}}$ & $\mathbf{k . €}$ & $\mathbf{\epsilon} / \mathbf{m}^{\mathbf{3}}$ \\
\hline Electric Power & 2536.60 & 0.31 & 2536.60 & 0.35 \\
Membrane Replacement & 0.00 & 0.00 & 121.04 & 0.02 \\
Chemicals Consumables & 156.65 & 0.02 & 46.28 & 0.01 \\
Maintenance and Parts & 369.36 & 0.05 & 369.36 & 0.05 \\
Supervision and Labor & 235.86 & 0.03 & 235.86 & 0.03 \\
\hline Total & 3298.47 & 0.41 & 3309.15 & 0.46 \\
\hline
\end{tabular}

Moreover, in another case study (Table 3) [38], it was concluded that the total investment in the $90,000 \mathrm{~m}^{3} / \mathrm{d}$ plant was about $56.2 \mathrm{M} €$ in the case of conventional granular filtration, whereas 59.3 M€ were needed for UF plant (Table 3). The higher cost of UF systems $\left(0.47 € \mathrm{~m}^{-3}\right)$ in compare with conventional treatment systems $\left(0.44 € \mathrm{~m}^{-3}\right)$, is attributed to the capital and the fixed operational and maintenance cost. 
Table 3. Comparative costs for a water membrane filtration unit and a conventional granular filtration system.

\begin{tabular}{ccccc}
\hline \multirow{2}{*}{ Parameter } & \multicolumn{2}{c}{ Conventional Filtration System } & \multicolumn{2}{c}{ Ultrafiltration Membranes } \\
\cline { 2 - 5 } & $\mathbf{k . €}$ & $\mathbf{\epsilon} / \mathbf{m}^{\mathbf{3}}$ & $\mathbf{k . €}$ & $\mathbf{\epsilon} / \mathbf{m}^{\mathbf{3}}$ \\
\hline Capital cost & 5900.93 & 0.20 & 6169.72 & 0.21 \\
Fixed Operational and & 1946.51 & 0.07 & 2458.28 & 0.08 \\
Maintenance cost & 4284.63 & 0.14 & 4279.29 & 0.14 \\
Energy cost & 1286.10 & 0.06 & 718.26 & 0.01 \\
Chemicals cost & $13,418.17$ & 0.47 & $13,625.55$ & 0.44 \\
\hline Total & &
\end{tabular}

From an industrial-scale case study at Kelantan-Malaysia where evaluation of both UF and granular filtration systems was conducted [39], it was estimated that capital cost for a $11,000 \mathrm{~m}^{3} / \mathrm{d}$ conventional granular filtration system would have a construction cost around $2.48 \mathrm{M} €$ while the actual cost of a 14,000 $\mathrm{m}^{3} / \mathrm{d}$ UF system was $3.26 \mathrm{M} €$ in 2013 . The UF system construction cost would be $242 € / \mathrm{m}^{3}$ of treated water capacity compared with $229 € / \mathrm{m}^{3}$ for the conventional system. An important advantage of membrane systems is that they require less space compared to the conventional water-treatment system. The construction cost for a UF system is only $5.6 \%$ higher but it requires $69.6 \%$ less space than the conventional system, which indicates that once the land value reached or exceeded a value point $/ \mathrm{m}^{2}$, the UF system capital expenditure (for both $14 \mathrm{ML} / \mathrm{d}$ and $11 \mathrm{ML} / \mathrm{d}$ ) would become much lower. The estimated operational cost for the UF system was more than 2 times higher than the conventional system mainly because of the higher electricity use due to the pressure driven membrane filtration process and the washing chemicals. To decrease electricity cost, an alternative way is the use of renewable energy resources such as solar energy or hydroelectricity.

The most outstanding advantages of UF system are the basic operation mechanism (surface filtration) which does not require prior coagulation-flocculation process unlike the conventional system the reduction in the chemical cost which was $\sim 3 \%$ compared to the conventional system [39]. As is described in [39], cleaning cost of ultrafiltration-chemical cleaning of membranes-was $46 \%$ of that of conventional system (cleaning of sludge in clarifier and sand-beds). On the other hand, automation equipment maintenance and piping repair was $210 \%$ of that of conventional system, as it was designed to be fully automated with minimal operators' intervention while the sand-bed filtration system requires operators' manual adjustment on coagulant dosage and filter media backwash. The main water losses are due to filter/membrane cleaning and sludge discharge and are critical issues at certain locations whereby the natural water resources have very limited feed water flow to the treatment plants. Data [39] show that the UF system accompanied by higher water losses $\sim 11 \%$ compared to the conventional system water losses of only $6.6 \%$. Another issue that should be noted is the composition of the discharged sludge and solids suspension. It has been estimated that aluminum sludge treatment and disposal could lead to $0.05 € / \mathrm{m}^{3}$ increase of the overall operational cost of the conventional/sand-bed water production. A sustainable water-treatment system could achieve long-term economic profit with minimal environmental impact.

Presently, conventional processing is the main preferred technology due to lower investment costs and lack of UF application experience. The most common reason for applying membrane filtration was to meet regulatory requirements for drinking water as it constitutes an absolute barrier to organic and inorganic particulates, protozoa, bacteria and in a significant level of viruses. However, because membrane technology has become cost-competitive with conventional processes, other factors such as the smaller land requirements and the ability to treat variable turbidity / quality water make membrane filtration more attractive for water suppliers. 


\section{Conclusions}

In the present study, a comparison of the performance of a depth sand filter and a UF membrane for the filtration of kaolinite suspensions simulating Grafkos river raw water (Achaia, Greece) was performed to adopt the best practice for the environment considering chemical reagents and the required water volumes for backwashing.

The experimental results obtained using the UF unit, showed excellent filtration capabilities, exhibiting the ability to produce constantly high quality of filtrate water independently of the turbidity fluctuation of the feed water. With operation time and for increasing flow rate or high values of initial turbidity, permeability, and clean water flux were noticeably reduced. The sludge discharged from the UF washing procedure had similar characteristics with raw water presenting higher solid content but was characterized by smaller environmental impact due to the absence of aluminum and other chemical additives. The operational costs of the membrane unit can be minimized using membranes with pores size appropriate for the intrinsic characteristics of the suspensions, i.e., molecular size and charge.

In the case of deep sand filter, experiments showed that the surface loading of the filter significantly affects the process, and thus the filtration capacity is a decreasing function of the flow rate. High flow rates gave higher filtration rates, bigger volumes of clean water but intensive particle deposition at higher depths of the sand filter leading to lower superficial speed. The use of deeper bed filters becomes necessary to achieve the same volume of filtrate water with the corresponding increase in installation cost.

Concluding, deep-bed filtration, is a method of lower energy consumption but requires skilled operation and maintenance. It is not an environmentally friendly process since it requires significant chemical pre-treatment and appropriate management of residuals and sludge, as well as its efficiency is reduced with turbidity increase e.g., in case of rainfalls. In contrast, the UF membrane process has become more attractive due to the increased stringency of the drinking water regulations, the smoother operation, the small space footprint, and its environmental sustainability due to reduction of chemicals and waste treatment.

Author Contributions: Conceptualization, C.A.P. and V.G.P.; methodology, C.A.P. and V.G.P.; investigation F.K.K.; data curation, F.K.K. and V.S.; writing - original draft preparation, F.K.K.; writingreview and editing, V.S. and C.A.P.; supervision, C.A.P. and V.G.P. All authors have read and agreed to the published version of the manuscript.

Funding: This research received no external funding.

Institutional Review Board Statement: Not Applicable.

Informed Consent Statement: Not Applicable.

Conflicts of Interest: The authors declare no conflict of interest.

\section{References}

1. Zhou, Z.; Huang, T.; Ma, W.; Li, Y.; Zeng, K. Impacts of water quality variation and rainfall runoff on Jinpen Reservoir, in Northwest China. Water Sci. Eng. 2015, 8, 301-308. [CrossRef]

2. World Health Organization. Guidelines for Drinking Water Quality 2004; World Health Organization: Geneva, Switzerland, 2011.

3. Osadchyy, V.; Nabyvanets, B.; Linnik, P.; Osadcha, N.; Nabyvanets, Y. Characteristics of Surface Water Quality. In Processes Determining Surface Water Chemistry; Springer: Cham, Switzerland, 2016; pp. 1-9.

4. Hoslett, J.; Massara, T.; Malamis, S.; Katsou, E.; Ahmad, D. Surface water filtration using granular media and membranes: A review. Sci. Total Environ. 2018, 639, 1268-1282. [CrossRef]

5. Goransson, G.; Larson, M.; Bentz, D. Variation in turbidity with precipitation and flow in a regulatedriver system-river Göta Alv, SW Sweden. Hydrol. Earth Syst. Sci. 2013, 10, 255-293.

6. Ling, T.; Soo, C.; Liew, J.; Nyanti, L.; Grinang, J. Influence of Rainfall on the Physicochemical Characteristics of a Tropical River in Sarawak, Malaysia. Pol. J. Environ. Stud. 2017, 26, 2053-2065. [CrossRef]

7. Maier, M.M.; Pepper, I.L.; Gerba, C.P. Environmental Microbiology, 2nd ed.; Elsevier: Amsterdam, The Netherlands, 2009.

8. AWWA. Microfiltration and Ultrafiltration Membranes for Drinking Water: Manual for Water Supply Practices, M53. J. Am. Water Works Assoc. 2008, 100, 84-97. [CrossRef] 
9. Alspach, B.; Adham, S.; Cooke, T.; Delphos, P.; Garcia-Aleman, J.; Jacangelo, J.; Karimi, A.; Pressman, J.; Schaefer, J.; Sethi, S. Microfiltration and ultrafiltration membranes for drinking water. J. Am. Water Work. Assoc. 2008, 100, 84-97.

10. Yamamura, H.; Kimura, K.; Watanabe, Y. Mechanism involved in the evolution of physically irreversible fouling in Microfiltration and ultrafiltration membranes used for drinking water treatment. Environ. Sci. Technol. 2007, 41, 6789-6794. [CrossRef]

11. Yamamura, H.; Kimura, K.; Higuchi, K.; Ding, Q.; Hafuka, A. Tracking inorganic foulants irreversibly accumulated on lowpressure membranes for treating surface water. Water Res. 2015, 87, 218-224. [CrossRef] [PubMed]

12. Howe, K.J.; Clark, M.M. Fouling of Microfiltration and ultrafiltration membranes by natural waters. Environ. Sci. Technol. 2002, 36, 3571-3576. [CrossRef]

13. Teixeira, C.; Ghisi, E. Comparative Analysis of Granular and Membrane Filters for Rainwater Treatment. Water 2019, 11, 1004. [CrossRef]

14. Al-Ani, M.Y.; Hendricks, D.W.; Logsdon, G.S.; Hilber, C.P. Removing Giardia Cysts from Low Turbidity Waters by Rapid Rate. J. Am. Water Work. Assoc. 1986, 78, 66-73. [CrossRef]

15. Joseph, L.; Flora, J.; Park, Y.; Badawy, M.; Saleh, H. Removal of natural organic matter from potential drinking water sources by combined coagulation and adsorption using carbon nanomaterials. Sep. Purif. Technol. 2012, 95, 64-72. [CrossRef]

16. Chowdhury, S. Trihalomethanes in drinking water: Effect of natural organic matter distribution. Water Sa 2013, 39, 1-8. [CrossRef]

17. Özdemir, K. Characterization of Natural Organic Matter in Conventional Water Treatment Processes and Evaluation of THM Formation with Chlorine. Sci. World J. 2014, 2014, 1-7. [CrossRef]

18. Marais, S.; Ncubea, E.; Mambab, B. Comparison of natural organic matter removal by ultrafiltration, granular activated carbon filtration and full scale conventional water treatment. J. Environ. Chem. Eng. 2018, 6, 6282-6289. [CrossRef]

19. Rondeau, V.; Jacqmin-Gadda, H.; Commenges, D.; Helmer, C.; Dartigues, J.-F. Aluminum and silica in drinking water and the risk of Alzheimer's disease or cognitive decline: Findings from 15-year follow-up of the PAQUID cohort. Am. J. Epidemiol. 2009, 169, 489-496. [CrossRef] [PubMed]

20. Domand, A.; Rinaudo, M.; Terrasin, C. Adsorption of chitosan and a quaternized derivative on kaolin. J. Appl. Polym. Sci. 1989, 38, 1799-1806.

21. Katrivesis, F.K.; Karela, A.D.; Papadakis, V.G.; Paraskeva, C.A. Revisiting of coagulation-flocculation processes in the production of potable water. J. Water Process Eng. 2019, 27, 193-204. [CrossRef]

22. Kuan-Mu, Y.; Mohammand, H.; O’Melia, C.R. Water and wastewater filtration. Concepts and applications. Environ. Sci. Technol. 1971, 5, 1105-1112.

23. Salkar, V.; Tembhurkar, A. Effect of $\zeta$-Potential of Influent Particles on Initial Filter Coefficient for Rapid Sand Filters. J. Water Chem. Technol. 2019, 41, 188-196. [CrossRef]

24. Dale, A.; Lowry, G.; Casman, E. Accurate and fast numerical algorithms for tracking particle size distributions during nanoparticle aggregation and dissolution. Environ. Sci. Nano 2017, 4, 89-104. [CrossRef]

25. Huangfu, X.; Ma, C.; He, Q.; Jiang, J. Effective removal of trace thallium from surface water by nanosized manganese dioxide enhanced quartz sand filtration. Chemosphere 2018, 189, 1-9. [CrossRef] [PubMed]

26. Li, H.; Jiang, L.; Li, H. Application of Ultrafiltration Technology in Water Treatment. Earth Environ. Sci. 2018, 186, 012009. [CrossRef]

27. Strathmann, H. Membranes and Membrane Separation Processes, 1. Principles; Wiley-VCH Verlag GmbH \& Co. KGaA: Weinheim, Germany, 2011.

28. Nqombolo, A.; Mpupa, A.; Moutloali, R.; Nomngongo, P. Wastewater Treatment Using Membrane Technology. In Wastewater and Water Quality; Yonar, T., Ed.; IntechOpen: London, UK, 2018; pp. $29-40$.

29. Choi, H.; Zhang, K.; Dionysiou, D.; Oerther, D. Influence of cross-flow velocity on membrane performance during filtration of biological suspension. J. Membr. Sci. 2005, 248, 189-199. [CrossRef]

30. Yin-Ru, C.; Yu-Jen, L.; Duu-Jong, L. Membrane fouling during water or wastewater treatments: Current research updated. J. Taiwan Inst. Chem. Eng. 2019, 94, 88-96.

31. Khalili, N.R.; Duecker, S.; Ashton, W.; Chavez, F. From cleaner production to sustainable development: The role of academia. J. Clean. Prod. 2015, 96, 30-43. [CrossRef]

32. Plakas, K.V.; Karabelas, A.J. Water treatment by nanofiltration membranes for retention of toxicorganic micropollutants-Performance and perspectives. In Proceedings of the 4th Environmental Conference of Macedonia, Thessaloniki, Greece, 18-20 March 2011.

33. Ang, W.L.; Mohammand, A.W.; Hilal, N.; Leo, C.P. A review on the applicability of integrated/hybrid membrane processes in water treatment and desalination plants. Desalination 2015, 363, 2-18. [CrossRef]

34. Bogati, R.; Goodwin, C.; Marcshall, K.; Leung, K.T. Optimization of Chemical Cleaning for Improvement of Membrane Performance and Fouling Control in Drinking Water Treatment. Drink. Water Treat. Sep. Sci. Technol. 2015, 50, 1835-1845. [CrossRef]

35. Qin, J.; Lay, W.; Kerke, K. Recent developments and future challenges of forward osmosis for desalination: A review. Desalination Water Treat. 2012, 39, 1-3. [CrossRef]

36. Uyak, V.; Koyuncu, I.; Okten, I.; Cakmakci, M. Removal of trihalomethanes from drinking water by nanofiltration membranes. J. Hazard. Mater. 2008, 152, 789-794. [CrossRef]

37. Moch, I. A 21st century study of global SWRO operating and capital costs. In Proceedings of the I.D.A World Congress on Desalination and Water Reuse, Manama, Bahrain, 8-13 March 2002.

38. Glueckstern, P.; Priel, M. Comparative cost of UF vs conventional pretreatment for SWRO systems. Int. Desalination Water Reuse Q. 2003, 13, 34-39.

39. Chew, C.M.; Mohamed, A.K.; Mohd, H.A.; Wan, M.Z. Evaluation, modelling and control of ultrafiltration membrane water treatment systems. J. Clean. Prod. 2016, 112, 3152-3163. [CrossRef] 